\title{
A ATUAÇÃO DO MINISTÉRIO PÚBLICO NO COMBATE À CORRUPÇÃ̃O: OPORTUNIDADE DE RESGATE DA CIDADANIA
}

\author{
Angela Giovanini Moura ${ }^{1}$
}

\section{Resumo}

O presente artigo faz uma reflexão sobre o enfrentamento da corrupção e da improbidade administrativa, no Estado Democrático de Direito, por meio de mecanismos legais de combate, entre o Ministério Público e demais atores legitimados, com a efetiva participação da sociedade civil no processo. Embora a vulnerabilidade à corrupção não seja característica única do aparelhamento estatal, atingindo também, a esfera privada, o enfoque teórico do trabalho situouse apenas no âmbito da organização estatal. Utilizando o método dialético, abordou-se os impactos negativos que a corrupção imprime à sociedade, minando a dignidade dos indivíduos, corroendo a democracia e deteriorando os serviços públicos prestados pelo Estado. Enfatizou-se o papel do Ministério Público, enquanto agente de transformação social, na prevenção das práticas corruptas, mediante articulação de políticas públicas que promovam o fortalecimento dos valores éticos da sociedade.

Palavras-chaves: Corrupção. Improbidade. Ministério Público. Cidadania.

\section{INTRODUÇÃO}

São diversas as teorias construídas, no campo da ciência política, com o propósito de explicar e compreender a corrupção, fenômeno mundial, observado em diversos países, independentemente do regime de governo adotado. Relacionada com valores sociais negativos, incorporados pelo cidadão, a corrupção é inerente a cada sociedade e, por isso, reclama, no Brasil, a conscientização da cidadania, como elemento essencial ao êxito de quaisquer das frentes de combate eleitas para o enfrentamento do problema.

As práticas corruptas e ímprobas apresentam-se sob as mais variadas formas e se caracterizam pelo alto grau de operatividade, em constante aprimoramento, desafiando a ação dos órgãos incumbidos na defesa do patrimônio público.

Integrando a agenda política do Estado brasileiro, o combate à corrupção tem buscado, a partir da pesquisa científica, a delimitação da dimensão danosa que a prática imprime ao regime democrático e o conhecimento dos fenômenos institucionais em que está associada. Destarte, mister se faz o reconhecimento de que instituições governamentais fortalecidas, no sistema

1 Graduação em Direito - Instituição Toledo de Ensino (1987). Professora adjunta na Faculdade de Direito em Quirinopolis. É titular da segunda promotoria de justiça de quirinopolis. Integrante da Associação Brasileira dos Membros do Ministério Público do Meio Ambiente- Abrampa. Mestre em Direito, Relações Internacionais e Desenvolvimento, pela PUC-Goias.

Revista da Faculdade Mineira de Direito, v.12, n. 23, jan./jun. 2011 - ISSN 1808-9429. 
político e econômico do País, funcionariam como escudo resistente à instalação de práticas corruptas.

A corrupção, ao diminuir a resistência ética das instituições e consumir os valores da democracia, ameaça a estabilidade e a segurança da sociedade, comprometendo o desenvolvimento do Estado de Direito, visto que as práticas corruptas são meios de fortalecimento do crime organizado.

Neste prisma, importa destacar a observação de Gomes (2009, p.14):

As organizações criminosas sabem onde a presença do Estado deixa brechas e ali florescerá. Dessa deficiência estatal, de um estado fraco que antes não provia as necessidades sociais, surgirá o crime organizado que, como uma bola de neve, o tornará mais debilitado ainda e com menor possibilidade de suprir a carência da população, que será cooptada pelas organizações criminosas, seja pela sua participação ou pela simples omissão com o silêncio.

A organização não governamental Transparência Internacional, engajada na luta contra a corrupção, tem produzido relatórios anuais com o fito de analisar os índices de percepção de corrupção dos países do mundo, elencando-os de acordo com o grau de corrupção entre autoridades públicas e políticas. Os últimos relatórios ${ }^{2}$ apontam a posição preocupante do Brasil no ranking global de corrupção, denunciando o impacto negativo imposto pelo fenômeno à sociedade, uma vez que a corrupção, além de ser a causa da deficiência dos serviços públicos, os quais devem ser prestados de forma eficaz aos cidadãos, constitui barreira para a superação destas deficiências.

Importa esclarecer, que a ONG Transparência Internacional dedica-se ao combate à corrupção e calcula anualmente, desde 1995, o Índice de Percepção da Corrupção (CPI, em inglês) para mais de 100 países. Neste índice, cada país recebe uma nota de zero (país muito corrupto) a 10 (país pouco corrupto). Trata-se de dados baseado em pesquisas de opinião de um conjunto de empresários e instituições acerca de suas percepções sobre práticas corruptas.

A repressão do problema demanda adoção de políticas públicas sociais sérias, resgate de valores éticos e morais, combate à pobreza, por meio de geração de empregos, saneamento básico e moradia (GOMES, 2009).

2 Disponível em < http://www.transparency.org/publications/annual_report> Acesso em 30/11/2011>.

Revista da Faculdade Mineira de Direito, v.12, n. 23, jan./jun. 2011 - ISSN 1808-9429. 
A democracia participativa, como corolário do Estado Democrático de Direito, deve ser urgentemente estimulada, incentivando-se a sociedade a acompanhar ativamente o uso adequado dos recursos públicos, por meio dos portais de transparência, em sítios disponíveis na Internet.

Neste contexto, o Ministério Público, em razão das funções constitucionais que exerce, assume postura de destaque e relevância para o enfrentamento da corrupção e da improbidade administrativa no aparelhamento estatal, não apenas por meio exclusivo dos mecanismos de investigação e ação judicial e extrajudicial à sua disposição, mas sobretudo como articulador de políticas públicas que promovam melhoria na educação e no bem-estar da coletividade, além da iniciativa na implementação de projetos, na órbita institucional, voltados para a conscientização da sociedade à prevenção das práticas corruptas.

\section{DESENVOLVIMENTO}

\subsection{Corrupção e Improbidade: aspectos históricos e conceituais}

A história da humanidade é permeada por práticas corruptas. A imagem bíblica de Adão e Eva, estampada no primeiro livro do Pentateuco Mosaico, é o primeiro registro arquétipo de corrupção.

Os pensadores gregos enfrentavam o tema com energia, porquanto temiam contaminar a pureza de suas ideias. A idealização socrática de um projeto político em harmonia com a Justiça, registrado por Platão em sua obra A República, procurava encontrar um método eficaz para impedir que a corrupção e a incompetência tomassem conta do poder público. No século IV antes de Cristo, Aristóteles, em seus escritos sobre a Geração e a Corrupção, compreendia esta última como um fato de dissolução e de destruição da convivência social.

$\mathrm{Na}$ sociedade Romana a corrupção tornou-se endêmica ante as imunidades legais previstas a certos estamentos da sociedade, levando a divisão do império no ano de 395, conforme acentua Filgueiras (2008-a).

A trajetória da organização da sociedade humana, segundo registros literários, é pontuada pela corrupção, evidenciando que o fenômeno não é contemporâneo, muito embora, no passado, lhe fosse dada uma conotação diferenciada dos contornos atuais conferidos pela teoria política moderna.

No Brasil, a corrupção recua ao período da colonização portuguesa, época em que as práticas mercantilistas da colonização voltadas ao extrativismo despertavam a cobiça, 
favorecendo o suborno. Dean (1996) assinala que, em 1605, a Coroa Portuguesa constatou que funcionários régios, atuando no Brasil como guardas florestais, na fiscalização do corte ilegal e contrabando da madeira, facilitavam o comércio ilegal de pau-brasil e de outras riquezas brasileiras, como ouro e diamante.

A construção do Estado brasileiro foi marcada por atos de corrupção, prosseguindo nos dias atuais, sem encontrar qualquer resistência, mesmo diante do princípio republicano da moralidade que deve nortear a administração pública.

Atualmente, o país experimenta casos de corrupção que penetram o sistema democrático e se entrelaçam com o crime organizado, visto que a globalização, ao permitir diversas interações entre os atores globais, resultou na fragilidade da fronteira estatal, tornando um desafio para um país monitorar todos seus fluxos internacionais (SANDRONI, 2010).

A corrupção vem se disseminando no Brasil e, instalando-se sorrateiramente, busca enfraquecer as estruturas estatais, ameaçando a democracia. A permanência, como uma de suas características, no aparelho estatal, impõe desafios àqueles que procuram combatê-la, uma vez que o mal, enraizado profundamente, se apresenta impossível de ser extirpado. Neste sentido, o combate à corrupção deve, igualmente, pautar-se pela permanência, de forma a dificultar sua prática, reprimindo-a, constante e paulatinamente.

De origem latina, o termo está associado a ideias de decomposição, putrefação, depravação, desmoralização, sedução e suborno. Geralmente, a corrupção se vincula ao exercício do poder, por meio do qual a obtenção de vantagens, para o atendimento de satisfações pessoais, se realiza de forma imoral e ilegal, justamente por quem deveria se manter no zelo e no respeito pela coisa pública.

Segundo Nye (1967), a corrupção é um desvio dos deveres associados a um cargo público para o benefício privado. Mas este conceito pode ser estendido para englobar o benefício a partidos políticos, familiares e classes.

Sabella (2010) compreende o termo corrupção como qualquer conduta humana impregnada de desvalor ético ou violadora dos princípios que norteiam a atividade administrativa.

Para Filgueiras (2008-b), a teoria política da corrupção está relacionada a fins normativos, tornando-se atualmente um desvio das regras legais, embora em épocas remotas se vinculasse a questões de valores morais e virtudes cívicas.

Revista da Faculdade Mineira de Direito, v.12, n. 23, jan./jun. 2011 - ISSN 1808-9429. 
A disseminação da corrupção no Estado brasileiro é apontada como consequência da dissociação que se verifica entre a ética e a política, por parte de muitos daqueles que ocupam o poder estatal, em desprezo às questões éticas para a satisfação do interesse privado.

Neste aspecto, Pasquino (apud BOBBIO, 1998), conceitua a corrupção sob diferentes prismas:

\begin{abstract}
Assim se designa o fenômeno pelo qual um funcionário público é levado a agir de modo diverso dos padrões normativos do sistema, favorecendo interesses particulares em troco de recompensa. Corrupto é, portanto, o comportamento ilegal de quem desempenha um papel na estrutura estadual. Podemos distinguir três tipos de Corrupção: a prática da peita ou uso da recompensa escondida para mudar a seu favor o sentir de um funcionário público; o nepotismo, ou concessão de empregos ou contratos públicos baseados não no mérito, mas nas relações de parentela; o peculato por desvio ou apropriação e destinação de fundos públicos ao uso privado.
\end{abstract}

A corrupção, em qualquer de suas vertentes, guarda estreita relação com a improbidade. Contudo, o conceito de improbidade, conferido pela Lei de Improbidade, $\mathrm{n}^{\circ}$ 8.429/92, mormente nos artigos 9, 10 e 11, situa a corrupção como uma das formas de materialização da improbidade administrativa.

A corrupção é conduta tipificada no Código Penal, enquanto os atos de improbidade possuem natureza civil. Para a Lei $n^{\circ} 8.429 / 1992$, constituem atos de improbidade administrativa as condutas perpetradas pelos agentes públicos que causem lesão ao erário e que atentem contra os princípios da administração pública.

A improbidade administrativa consiste na violação aos princípios da administração pública, como a moralidade, a boa-fé, a lealdade, entre outros. $\mathrm{O}$ artigo $37, \S^{\circ}$, da Constituição Federal de 1988, estabeleceu rigorosas sanções para a violação dos princípios que norteiam a administração pública, como a suspensão dos direitos políticos, a perda da função pública, a indisponibilidade de bens e o ressarcimento ao erário.

Neste diapasão, afirma Caetano (2010) que

a probidade administrativa consiste no dever de o funcionário servir à administração com honestidade, procedendo no exercício das funções, sem aproveitar os poderes ou facilidades delas decorrente em proveito próprio pessoal ou de outrem a quem queria favorecer.

Antes da entrada em vigor da Lei $\mathrm{n}^{\circ}$ 8.429/92, as práticas corruptas que causassem danos ao erário ou que importassem em enriquecimento ilícito do servidor público eram punidas com

Revista da Faculdade Mineira de Direito, v.12, n. 23, jan./jun. 2011 - ISSN 1808-9429. 
sequestro e perdimento de bens. Com a edição da Lei de Improbidade, houve uma ampliação das sanções aplicáveis à espécie.

As disposições da Lei de Improbidade Administrativa não se restringem ao agente público, sendo também aplicáveis a terceiros que, mesmo não se revestindo desta qualidade, induzem ou concorrem à prática de conduta ímproba ou dela se beneficiam sob qualquer forma direta ou indireta.

A primeira espécie de improbidade administrativa é tratada pelo artigo $9^{\circ}$, da referida lei. Configura-se com o enriquecimento ilícito auferido por meio de vantagem patrimonial indevida, praticada por agentes públicos ou terceiros que concorreram para o ato.

Procurando garantir proteção ao patrimônio público, o legislador elencou no artigo 10, da citada legislação, as ações ou omissões, culposas ou dolosas, dos agentes que causem lesão ao erário, como o desvio, apropriação, malbaratamento ou dilapidação dos bens públicos.

A terceira forma de improbidade administrativa, nos termos do art. 11, decorre de atos ou omissões que atentem contra os princípios da administração, discriminados igualmente no caput do art. 37, da Constituição Federal de 1988, consubstanciados nos deveres de honestidade, imparcialidade, legalidade e lealdade às instituições.

A responsabilidade decorrente da prática de atos de improbidade administrativa pode alcançar o âmbito penal, civil e administrativo. As sanções são cumulativas em razão do alto grau de censura conferido pela legislação à conduta do agente ímprobo ou do terceiro que contribui para o crime.

\subsection{O Ministério Público e os mecanismos de combate à corrupção}

Os impactos negativos que as práticas corruptas imprimem à democracia e à cidadania exigem prioridade absoluta na construção de uma agenda com medidas de combate ao problema, porquanto o custo da corrupção, representado pelo escoamento de recursos, que deixa de ser

aplicado na saúde, educação, segurança, pesquisa científica, tecnologia etc., para alimentar organizações criminosas, compromete os serviços públicos prestados aos cidadãos.

Ao alimentar o crime, o país concorre para a queda do índice de desenvolvimento humano, necessário para situá-lo no patamar dos países desenvolvidos, bem como perde competitividade no mercado internacional.

Revista da Faculdade Mineira de Direito, v.12, n. 23, jan./jun. 2011 - ISSN 1808-9429. 
Os custos da corrupção refletem na execução eficiente de políticas públicas, prejudicando a qualidade de vida dos cidadãos, sobretudo nas áreas de educação e saúde, afetando o sentido de igualdade e de justiça social, além de disseminar um sentimento de desconfiança de toda a sociedade em relação às instituições.

O desvio de verbas públicas para o atendimento de interesses ilícitos gera externalidades negativas, traduzidas em custos sociais que serão debitados ao cidadão, minando-lhe a dignidade.

Estudos realizados têm identificado um conjunto de causas que geram ou podem gerar a corrupção (MAURO, 1997 e RAMALHO, 2006), os quais apontam o elevado poder discricionário, porque criam oportunidades para práticas corruptas; o baixo nível de salários, por estimularem à busca de fontes alternativas para completar a renda e isto pode ocorrer tanto com os funcionários do setor público quanto do setor privado; o sistema político, ante a tendência manifestada pela competição política; e, aceitação da desigualdade social e de direitos, por promoverem a impunidade sobre práticas corruptas.

Podendo ser apontada como uma das causas decisivas da pobreza do país, a corrupção “corrói a dignidade do cidadão, contamina os indivíduos, deteriora o convívio social, arruína os serviços públicos e compromete a vida das gerações atuais e futuras”. (TREVISAN e al : 2003, p. 17).

As organizações criminosas se sustentam na corrupção. As empresas do crime crescem e se fortalecem na medida em que corroem a democracia. Disseminando práticas corruptas e delas se alimentando, as organizações criminosas enfraquecem as instituições públicas, aumentando, desta forma, as condições para a cooptação de novos integrantes às suas empreitadas.

As iniciativas para o enfrentamento da corrupção devem priorizar o fortalecimento dos mecanismos de prevenção, como também diminuir a impunidade, por meio de uma justiça mais rápida e eficiente, de modo a induzir a mudança do comportamento oportunista.

Neste contexto, destaca-se a função conferida ao Ministério Público pela ordem constitucional, instalada a partir de 1988, que conferindo-lhe soberania estatal, outorgou-lhe papel determinante no controle e na fiscalização da administração pública e do regime democrático.

O Ministério Público, portanto, tem a defesa do interesse público como finalidade outorgada pela Constituição Federal de 1988, nos artigos 127 e 129 (BRASIL, 2001, p.82-82):

Revista da Faculdade Mineira de Direito, v.12, n. 23, jan./jun. 2011 - ISSN 1808-9429. 
Art. 127. O Ministério Público é instituição permanente, essencial à função jurisdicional do Estado, incumbindo-lhe a defesa da ordem jurídica, do regime democrático e dos interesses sociais e individuais indisponíveis.

$\S 1^{\circ}$ - São princípios institucionais do Ministério Público a unidade, a indivisibilidade e a independência funcional.

Art. 129. São funções institucionais do Ministério Público:

III - promover o inquérito civil e a ação civil pública, para a proteção do patrimônio público e social, do meio ambiente e de outros interesses difusos e coletivos;

O novo modelo de Estado Democrático de Direito ampliou as atribuições conferidas ao Ministério Público para outorgar-lhe a função de garantidor dos direitos fundamentais conquistados historicamente e, sobretudo, do princípio da moralidade administrativa. Possui, assim, um dever ético-político de agir em nome da democracia, em busca da consolidação dos direitos sociais, difusos e coletivos.

Neste aspecto, imperioso ao Ministério Público a adoção de posturas pró ativas no cumprimento de suas funções institucionais para além de uma atuação meramente demandista, como meio de viabilizar o compromisso de transformar a realidade social e salvaguardar os direitos fundamentais (COSTA, in VITORELLI, 2011).

Diante deste panorama, iniciativas em prol do estabelecimento de parcerias com entidades de ensino e demais entidades formadas pela sociedade civil, objetivando a implementação de projetos permanentes que visem ampla divulgação das práticas corruptas e atos de improbidade administrativa, com viés esclarecedor e educativo, de forma a cooptar o cidadão para o engajamento na luta contra esta modalidade criminosa, poderia ensejar oportunidade valiosa para agregar-lhe valores positivos e diminuir possíveis campos de atuação para as organizações criminosas.

Por outro lado, a par da atuação ativista em âmbito preventivo, ainda conta o Ministério Público com eficazes instrumentos operacionais, como o inquérito civil e da ação civil pública, para defesa e garantia do patrimônio público e social, do meio ambiente e de outros interesses difusos e coletivos, como a moralidade administrativa.

O inquérito civil é ferramenta eficiente à função instrumental do Ministério Público na investigação e no combate aos atos de corrupção, tendo como finalidade a coleta de elementos seguros da ocorrência do ato de improbidade administrativa, assim como da respectiva autoria.

A Lei da Ação Civil Pública, no 7.347, de 24 de julho de 1985, anterior ao texto constitucional, já tratava da responsabilização por danos causados ao meio ambiente, ao 
consumidor, a bens e direitos de valor artístico, estético, histórico, turístico e paisagístico, sendo recepcionada pela Constituição da República, consoante disposto no inciso III, do artigo 129.

Constata-se, pois, a importância da ação civil pública como instrumento constitucional repressivo para defesa judicial dos direitos fundamentais. Com efeito, a Lei Federal n ${ }^{\circ}$ 8.078, de 11 de setembro de 1990, que instituiu o Código de Defesa do Consumidor, incluiu o inciso IV no artigo $1^{\circ}$ da Lei da Ação Civil Pública, para fazer constar as ações de responsabilidade por danos morais e patrimoniais causados a qualquer outro interesse difuso e coletivo.

Indiscutível a legitimidade do Ministério Público para promover as medidas judiciais e extrajudiciais cabíveis, objetivando o cumprimento das propostas sociais, difusas e coletivas previstas na Constituição e, principalmente, no combate efetivo à corrupção institucionalizada, devendo estabelecer estratégias de atuação preventivas e repressivas para o êxito de sua missão.

O estabelecimento de parcerias, neste campo, desponta imprescindível para o êxito da missão ministerial. A contribuição de aliados é valiosa, podendo ser prestada pelos Tribunais de Contas, Comissões Parlamentares de Inquérito, Controladoria Geral da União, Receita Federal, Banco Central, Polícia Federal, entre outros órgãos corresponsáveis pelo combate à corrupção.

Merece destaque a iniciativa da Secretaria Nacional de Justiça do Ministério da Justiça que instituiu, em 2003, a Estratégia Nacional de Combate à Corrupção e à Lavagem de Dinheiro (ENCCLA) visando à articulação e à atuação conjunta entre órgãos públicos que trabalham com a fiscalização, o controle e a inteligência como forma de aperfeiçoar a prevenção e o combate à corrupção e à lavagem de dinheiro.

A ENCCLA consiste na articulação de diversos órgãos dos três poderes da República, Ministérios Públicos e da sociedade civil que atuam, direta ou indiretamente, na prevenção e combate à corrupção e à lavagem de dinheiro, com o objetivo de identificar e propor ajustes aos pontos falhos do sistema anti lavagem e anticorrupção.

Atualmente, cerca de 60 órgãos e entidades fazem parte da ENCCLA, tais como, Ministérios Públicos, Policiais, Judiciário, órgãos de controle e supervisão, como a Controladoria Geral da União, Tribunal de Contas da União, e outros, Banco Central, Agência Brasileira de Inteligência, Advocacia Geral da União, Federação Brasileira de Bancos, etc.

Vale ressaltar, que a promoção da ação civil pública não é exclusividade ministerial, podendo ser manejada pela União, Estados, Municípios, autarquias, empresas públicas, fundações, sociedades de economia mista ou por associações, desde que presentes os requisitos 
legais. No entanto, é o Ministério Público, segundo estatísticas, o principal utilizador deste instrumento constitucional, seja na defesa do patrimônio público e do princípio da moralidade administrativa, seja na defesa de outros interesses difusos e coletivos.

Como órgão garantidor do princípio constitucional da moralidade administrativa, o Ministério Público deve operacionalizar o combate à improbidade, investigando efetivamente corruptos e corruptores, com vistas à sua punição, ante a impotência da sociedade brasileira para a defesa da coisa pública contra os reiterados atos de corrupção, exigindo-se a intervenção ministerial na dinâmica entre os Poderes constituídos, para reduzir as desigualdades sociais e ampliar a consciência e o exercício da cidadania.

A propósito, é necessário desconstruir a postura histórica de aceitação da impunidade dos delitos e dos atos de corrupção, como estratégia de combate à reprodução contínua de novas práticas ímprobas. Indubitavelmente, a impunidade estimula a corrupção, acabando por torná-la tolerável no meio social.

A valorização exacerbada do patrimônio, bens e riquezas, enseja o tráfico de influência, a corrupção, a imoralidade administrativa, em prejuízo do agir honesto e correto. O erário é tido, muitas vezes, como extensão do patrimônio particular do administrador ou do agente político e as eventuais punições previstas na legislação nem sempre se efetivam, em razão da manipulação e dos recursos processuais sempre disponíveis aos poderosos.

A Convenção das Nações Unidas Contra a Corrupção, ratificada pelo Brasil por meio do Decreto $\mathrm{n}^{\circ} 4.410 / 2002$, ressalta a importância da responsabilidade dos Estados em relação à definitiva erradicação da impunidade, como medida imprescindível e eficiente no combate à corrupção.

Não se afigura surpreendente o livre trânsito do crime organizado na estrutura estatal, interferindo nos Poderes Judiciário, Legislativo e Executivo, a ponto de impor resistência às apurações dos grandes esquemas de corrupção.

Imperioso se torna, diante deste quadro, dar uma nova dimensão ao combate à corrupção e ao crime organizado, primando por fortalecer a atuação integrada e conjunta dos atores jurídicos, dentre advogados, membros do Ministério Público e do Judiciário, policiais civis e federais, utilizando-se da mesma dinâmica adotada pela cooperação internacional. Importante, ainda, o investimento no aprimoramento profissional e em novas técnicas de investigação dos 
mecanismos de corrupção, de modo a efetivar o princípio constitucional da moralidade administrativa e dos direitos fundamentais.

Por outro lado, é expressivo o entendimento de que as medidas repressivas, pelo efeito intimidatório que encerram, não se afiguram, por si só, como instrumentos eficazes no combate à corrupção, mormente para evitar a reiteração de novos atos ímprobos.

Assim, novos métodos de enfrentamento do problema, com foco numa atuação de ordem preventiva, agregando-se o poder público e a sociedade civil organizada, têm conquistado adeptos.

A eficácia das ações preventivas repousam no fato de se revelarem antes da prática corrupta, permitindo-se trabalhar os valores éticos e morais do cidadão quando sua personalidade ainda se encontra em processo de desenvolvimento.

Nesse sentido, a Convenção Interamericana contra a Corrupção, salienta a importância de ser estimulada a consciência da população local em relação à existência e à gravidade desse problema, bem como da necessidade de se reforçar a participação da sociedade civil na prevenção e na luta contra a corrupção.

Ainda, perpetuando-se a corrupção no seio da sociedade, por meio de práticas cotidianas desonestas, torna-se fundamental o fortalecimento dos padrões éticos para que possam refletir no exercício do poder estatal.

A atuação preventiva do Ministério Público no combate à corrupção, como articulador de políticas públicas, sensibilizando os poderes constituídos para a adoção de medidas capazes de enfrentar os problemas locais, pode se apresentar vantajosa na resolução dos conflitos sociais, dificultando práticas corruptas.

O controle preventivo da administração pública, efetivado pelo órgão ministerial, por meio de recomendações e de sugestões, objetivando a adoção de soluções consensuais para as demandas sociais, decorrente do seu dever constitucional de zelar pelo patrimônio e pela probidade pública, antecipa os objetivos perseguidos na esfera judicial, muitas vezes com maior êxito.

O combate à corrupção deve ser conduzido como um projeto institucional do órgão ministerial, considerando os diversos mecanismos de combate, priorizando-se as ações preventivas, até porque uma vez concretizada a corrupção, o ressarcimento integral dos danos causados ao erário pode se restar diminuído. Por se antecipar à consumação da prática corrupta,

Revista da Faculdade Mineira de Direito, v.12, n. 23, jan./jun. 2011 - ISSN 1808-9429. 
as estratégias de prevenção podem contribuir com resultados mais eficientes e positivos à sociedade brasileira.

Como agente de transformação social, a atuação preventiva do órgão ministerial no combate à corrupção, tem o objetivo estratégico de contribuir para a efetiva implantação dos direitos de cidadania e para a construção de uma sociedade justa, fraterna e solidária, comprometida com o respeito à coisa pública, com responsabilidade e compromisso ético.

\section{CONCLUSÃO}

A corrupção estatal produz danos que atentam contra a democracia, o patrimônio público, a soberania, a segurança nacional, o desenvolvimento econômico e social, a segurança pública, as instituições democráticas, a justiça social, o Estado Democrático de Direito e a ordem jurídica.

Diante disso, a corrupção, em todas as suas formas, não pode ser enfrentada apenas como infração à norma positivada. Impõe-se um aparato de investigação e combate que reúna mecanismos de informação e técnicas de inteligência para o enfrentamento do problema.

A acumulação de riquezas, que comanda o sistema capitalista no setor privado, não dita a atividade financeira do Estado, porquanto seu objetivo é o atendimento às necessidades coletivas e ao bem-estar social. Assim, é obrigação do Estado o fornecimento e a garantia de serviços como a educação, saúde, segurança, o desenvolvimento econômico e social, dentre outros serviços de interesse social necessários à elevação do índice de desenvolvimento humano.

O Ministério Público, como agente transformador da realidade social é chamado, nesta ordem, para estimular a participação social no combate a corrupção e improbidade, utilizando-se de estratégias de atuação que possam contribuir para o fortalecimento da cidadania, minando os mecanismos de cooptação, largamente utilizado pelo crime organizado.

A complexidade das práticas corruptas reclama do Ministério Público a adoção de estratégias de atuação, repressivas e preventivas, em várias linhas de enfrentamento, incrementando-se as técnicas de investigação, treinamento, cooperação internacional, articulação com os diversos atores, sobretudo com a sociedade civil organizada, na busca de alianças que garantam a eficiência e a eficácia de sua atuação.

Como órgão garantidor do princípio constitucional da moralidade administrativa, o Ministério Público deve fazer dos meios legais de combate à corrupção e à improbidade administrativa, à sua disposição, oportunidade de resgate da cidadania, porquanto a medida que

Revista da Faculdade Mineira de Direito, v.12, n. 23, jan./jun. 2011 - ISSN 1808-9429. 
contribui para construção de uma nova consciência cultural de moralidade, permitirá às futuras gerações incorporar novos valores éticos, rompendo com a tolerância atávica diante de atos ímprobos e desonestos que atualmente penetram as estruturas da sociedade civil e do Estado.

\begin{abstract}
This article is a reflection about the tactics to combat corruption and malfeasance in office in a democratic state, through legal mechanisms to combat between prosecutors and other legitimate actors, with the effective participation of civil society in the process. Although vulnerability to corruption is not unique feature of the state apparatus, reaching also the private sector, the theoretical focus of the work amounted to just under the state organization. Using the dialectical method, we analyzed the negative impact that corruption gives to society, destroying the dignity of individuals, undermining democracy and deteriorating public services provided by the State. They emphasized the role of the prosecutor, as an agent of social transformation for the prevention of corrupt practices, through the articulation of public policies that promote the strengthening of ethical values in society.
\end{abstract}

Keywords: Corruption. Malfeasance. Public Prosecutor. Citizenship.

\title{
REFERÊNCIAS
}

BOBBIO, Norberto; MATTEUCCI, Nicola; PASQUINO, Gianfranco. Dicionário de Politica. trad. Carmen C, Varriale et al; coord. trad. João Ferreira; rev. geral João Ferreira e Luis Guerreiro Pinto Cacais. - Brasília: Editora Universidade de Brasília, 1 la ed., 1998, p. 292.

BRASIL. Constituição da República Federativa do Brasil de 1988. Brasília: Senado Federal, Subsecretaria de Edições Técnicas, 2001.

BRASIL. Decreto n. 4410, de 07 de outubro de 2001. Promulga a Convenção Interamericana contra a Corrupção, de 29 de março de 1996. Disponível em <http://www.planalto.gov.br/ccivil_03/decreto/2002/D4410.htm> Acesso em 20/10/2011.

BRASIL. Lei Federal $\mathbf{n}^{\circ}$ 8.429, de 2 de junho de 1992. Disponível em: <http://www.planalto.gov.br/ccivil_03/LEIS/L8429.htm>. Acesso em 20/10/2011.

CAETANO, Marcello. Princípios fundamentais do direito administrativo. 3 a $^{\text {R }}$ Reimpressão Portuguesa. Coimbra: Almedina,2010, p. 398.

Convenção Interamericana contra a Corrupção. Disponível em: <http://www.cgu.gov.br/oea/convencao/arquivos/convencao.pdf>. Acesso em 28/10/2011

DEAN. Warren. A ferro e fogo. A história da devastação da Mata Atlântica brasileira. Trad. Cid Knipel Moreira. São Paulo: Companhia das Letras, 1996. 
FILGUEIRAS, Fernando. Marcos teóricos da corrupção. In: AVRITZER, Leonardo; BIGNOTTO, Newton; GUIMARÃES, Juarez e STARLING, Heloisa M. M. (orgs.). Corrupção: ensaios e críticas. Belo Horizonte: Editora UFMG, 2008-a, p. 353-362.

Corrupção, democracia e Legitimidade. Editora UFMG: Belo Horizonte, 2008-b, p. 359.

GOMES. Rodrigo Carneiro. O Crime Organizado na Visão da Convenção de Palermo. $2^{\circ}$ ed. Belo Horizonte: Del Rey, 2009.

NYE, Joseph S. Corruption and political development: a cost-benefit analysis. American Political Science Review. N. 61, p. 417-427, 1967.

MAURO, Paolo. Why worry about corruption? Economic Issues. Washington, D.C.:International Monetary Fund, $\mathrm{N}^{\circ}$ 6, 1997.

RAMALHO, Renato M. Corrupção, instituições e desenvolvimento. Escola de Economia de São Paulo, FGV, 2006, p.

SABELLA. Walter Pauloa. MINISTÉRIO PÚBLICO, COMBATE À CORRUPÇÃO E CONTROLE DAS POLÍTICAS PÚBLICAS <http://www.justitia.com.br/artigos/b29529.pdf> Acesso em 20/10/2011.

SANDRONI. Gabriela Araujo Universidade Estadual Paulista - UNESP. Grupo de Estudos sobre Corrupção (CNPQ). <http://www.mp.am.gov.br/index.php/centros-de-apoio/combate-aocrime-organizado> 2010. Acesso em 20/10/2011.

TREVISAN. Antoninho Marmo; CHIZZOTTI, Antonio; LANHEZ, João Alberto; CHIZZOTTI, José; VERILLO, Josmar. O combate à corrupção nas prefeituras do Brasil. São Paulo: Uol, 2003.

VITORELLI. Edilson. (org). Temas Aprofundados do Ministério Público Federal. Bahia, JusPodivm, 2011, p.47. 